\title{
How do detemir and glargine compare when added to oral agents in insulin-naïve patients with type 2 diabetes mellitus?
}

\author{
Jennifer B Marks
}

Nature Clinical Practice Endocrinology \& Metabolism (2008) 4: 490-491 [doi:10.1038/ncpendmet0900]

Published online doi:10.1038/ncpendmet0998
The Practice Point commentary published in the September 2008 issue contained two numerical errors.

The total daily dose of once-daily insulin detemir cited in the commentary was $0.78 \mathrm{IU} / \mathrm{kg}$. This was, in fact, the quantity of insulin calculated for total daily doses when combined from all insulin detemir patients; both those on oncedaily plus those on twice-daily dosing regimens. It was, therefore, incorrect to be compared to total daily dose for once daily insulin glargine treatments. The appropriate comparison should have been between only patients who completed the trial on once-daily insulin detemir ( $45 \%$ of the detemir completers) versus once-daily insulin glargine completers, with total once-daily doses amounting to $0.52 \mathrm{lU} / \mathrm{kg}$ for insulin detemir versus $0.44 \mathrm{IU} / \mathrm{kg}$ for insulin glargine.

The second numerical error resulted in a statement that more than one FlexPen ${ }^{\circledR}$ (Novo Nordisk, Bagsvaerd, Denmark) would be required for a patient on insulin detemir. The correct analysis, using the baseline body weight reported in the trial $(87.4 \mathrm{~kg})$, shows that FlexPen ${ }^{\circledR}$ containing $300 \mathrm{IU}$ of insulin detemir would suffice for at least 6 days for most patients on once daily regimens and at least 3 days dosing for twicedaily regimens totaling $1 \mathrm{IU} / \mathrm{kg}$ as reported, not 1 day as previously stated. 